\title{
Ophiobolin A induces paraptosis-like cell death in human glioblastoma cells by decreasing $\mathrm{BKCa}$ channel activity
}

\author{
M Bury ${ }^{1}$, A Girault ${ }^{2}$, V Mégalizzi', S Spiegl-Kreinecker ${ }^{3}$, V Mathieu', W Berger ${ }^{4}$, A Evidente ${ }^{5}$, A Kornienko ${ }^{6}$, P Gailly ${ }^{7}$, C Vandier ${ }^{2}$ \\ and R Kiss ${ }^{*, 1}$
}

Glioblastoma multiforme (GBM) is the most lethal and common malignant human brain tumor. The intrinsic resistance of highly invasive GBM cells to radiation- and chemotherapy-induced apoptosis accounts for the generally dismal treatment outcomes. This study investigated ophiobolin A (OP-A), a fungal metabolite from Bipolaris species, for its promising anticancer activity against human GBM cells exhibiting varying degrees of resistance to proapoptotic stimuli. We found that OP-A induced marked changes in the dynamic organization of the F-actin cytoskeleton, and inhibited the proliferation and migration of GBM cells, likely by inhibiting big conductance $\mathrm{Ca}^{2+}$-activated $\mathrm{K}^{+}$channel (BKCa) channel activity. Moreover, our results indicated that OP-A induced paraptosis-like cell death in GBM cells, which correlated with the vacuolization, possibly brought about by the swelling and fusion of mitochondria and/or the endoplasmic reticulum (ER). In addition, the OP-A-induced cell death did not involve the activation of caspases. We also showed that the expression of $\mathrm{BKCa}$ channels colocalized with these two organelles (mitochondria and ER) was affected in this programmed cell death pathway. Thus, this study reveals a novel mechanism of action associated with the anticancer effects of OP-A, which involves the induction of paraptosis through the disruption of internal potassium ion homeostasis. Our findings offer a promising therapeutic strategy to overcome the intrinsic resistance of GBM cells to proapoptotic stimuli.

Cell Death and Disease (2013) 4, e561; doi:10.1038/cddis.2013.85; published online 28 March 2013

Subject Category: Cancer

Glioblastoma multiforme (GBM), also known as grade IV astrocytoma, is the most common primary malignant brain tumor. ${ }^{1}$ Despite the use of aggressive surgical resection, intensified radiation therapy and concomitant chemotherapy with temozolomide, the 5-year overall survival rate for GBM patients remains $<10 \%$. $^{2}$ This extremely unfavorable prognosis for GBM patients is accounted for by tumor recurrence, arising in part from the tumor cells' intrinsic resistance to apoptosis. ${ }^{1,2}$ The resistance of GBM cells to proapoptotic stimuli is believed to be associated with genetic alterations, affecting the key regulatory molecules involved in mitogenic signaling, most prominently receptor tyrosine kinases and the PI3K-PTEN-Akt-signaling axis. Genetic alterations having an impact on regulatory and effector molecules, residing in the classical cell death networks of apoptosis, such as alterations of the TP53 gene, are also involved. ${ }^{1,3}$

The induction of paraptotic cell death could be an alternative and emerging strategy to trigger GBM cell death and to exploit apoptosis-independent programmed cell death (PCD) pathways for the development of novel GBM therapies. Paraptosis is a form of non-apoptotic cell death characterized by a process of vacuolization that begins with the physical enlargement of mitochondria and the endoplasmic reticulum (ER). ${ }^{4,5}$ This PCD does not involve the apoptotic characteristics of pyknosis, DNA fragmentation or caspase activation, and is known to require new protein synthesis. ${ }^{4}$ Although the mechanisms underlying paraptosis, in particular, the signals responsible for triggering mitochondrial and ER dilatation, have not yet been fully elucidated, they could be associated with the disruption of internal potassium ion homeostasis involving the big/large conductance $\mathrm{Ca}^{2+}$-activated $\mathrm{K}^{+}$ channel (BKCa). ${ }^{5}$

Ophiobolin A (OP-A) is a sesterterpenoid phytotoxin produced by pathogenic fungi of the genus Bipolaris, which usually infect rice, maize and sorghum. ${ }^{6,7}$ OP-A has been reported to cause ion leakage, block hexose transport in

\footnotetext{
${ }^{1}$ Laboratoire de Toxicologie, Faculté de Pharmacie, Université Libre de Bruxelles (ULB), Brussels, Belgium; ${ }^{2}$ INSERM U1069, Laboratoire Nutrition Croissance Cancer, Université de Tours, Tours, France; ${ }^{3}$ Department of Neurosurgery, Landesnervenklinik Wagner-Jauregg Hospital, Linz, Austria; ${ }^{4}$ Department of Medicine I, Comprehensive Cancer Center and Institute of Cancer Research, Medical University Vienna, Vienna, Austria; ${ }^{5}$ Dipartimento di Scienze Chimiche, Complesso Universitario Monte Sant'Angelo, Napoli, Italy; ${ }^{6}$ Department of Chemistry and Biochemistry, Texas State University, San Marcos, TX, USA and ${ }^{7}$ Laboratoire de Physiologie Cellulaire, Institut des Neurosciences, Université Catholique de Louvain, Brussels, Belgium

*Corresponding author: R Kiss, Laboratoire de Toxicologie, Faculté de Pharmacie, Université Libre de Bruxelles (ULB), Campus de la Plaine, Boulevard du Triomphe, Brussels 1050, Belgium. Tel: + 324776220 83; Fax: + 32233253 35; E-mail: rkiss@ulb.ac.be

Keywords: ophiobolin A; glioblastoma; paraptosis; BKCa channel

Abbreviations: $\mathrm{AO}$, acridine orange; $\mathrm{BKCa}$, Big conductance $\mathrm{Ca}^{2+}$-activated $\mathrm{K}^{+}$channel; $\mathrm{CHX}$, cycloheximide; ER, endoplasmic reticulum; FCM, flow cytometry; $\mathrm{GBM}$, glioblastoma multiforme; GG, global growth; $\mathrm{KCa}, \mathrm{Ca}^{2+}$-activated $\mathrm{K}^{+}$channel; $\mathrm{MRDO}$, maximum relative distance from the point of origin; OP, ophiobolin; $\mathrm{PCD}$, programmed cell death; SA- $\beta$-gal, senescence-associated $\beta$-galactosidase

Received 17.1.13; revised 19.2.13; accepted 25.2.13; Edited by A Verkhratsky
} 
higher plants ${ }^{8}$ and inhibit calmodulin activity. ${ }^{7}$ Cocucci et al. ${ }^{9}$ also demonstrated that the inhibition of proton extrusion by OP-A in plant cells was the result of an effect on the permeability of the plasma membrane to potassium. However, few reports have previously described the biological effects of OP-A on human cancer cells. OP-A was shown to induce apoptosis in mouse leukemia cells ${ }^{10}$ and potently inhibit human cancer cell growth, ${ }^{7}$ but the precise mechanisms of action have remained unclear.

In the current study, we characterized the OP-A-mediated effects on proliferation and migration, as well as death induction of human GBM cells, and found that OP-A triggers a paraptosis-like cell death. We also showed that the inhibition of the BKCa channel by OP-A most likely disrupts internal potassium ion homeostasis, which is responsible, at least in part, for this type of PCD.

\section{Results}

OP-A inhibits the growth and alters the cell cycle progression of GBM cells. Data obtained from the $\mathrm{NCl}$ (Developmental Therapeutic Program, Division of Cancer Treatment and Diagnosis) indicate that OP-A (Structure in Figure 1a) potently inhibits the proliferation of GBM cell lines (Figure 1b) through a possibly novel mechanism of action compared with the 763000 compounds in the $\mathrm{NCl}$ database. Indeed, the highest 'COMPARE correlation coefficients' for OP-A were $0.524-0.645$ found for five compounds, which are mainly antibiotics.

A subpopulation of GBM cells with self-renewal capacity and propensity of generating heterogeneous cancer cell populations, known as GBM stem cells, is highly resistant to conventional therapies. ${ }^{11,12}$ Thus, in this study, two established (U373-MG and T98G) and one primoculture (GL19)
GBM cell lines expressing GBM stem cell markers, such as nestin and CD44, were used (Figure 1c). Moreover, U373-MG and T98G were previously shown to contain the mutated p53 tumor-suppressor gene, making them resistant to proapoptotic stimuli. ${ }^{13,14}$

The half maximal inhibitory concentration $\left(\mathrm{IC}_{50}\right)$ values of OP-A for U373-MG, T98G and GL19 cells determined using dose-response curves (MTT colorimetric assay) were 0.87 , 1.9 and $3.7 \mu \mathrm{M}$, respectively (Figure $1 \mathrm{~d}$ ). Using quantitative video microscopy, we observed that OP-A had antiproliferative effects on GBM cells (Figures $2 a-c$ ). OP-A-treated GBM cells displayed, at their $I_{50}$ values, lower growth rates over time relative to control cells as measured by calculating the global growth (GG) indices (Figures 2d-f). Moreover, we used flow cytometry (FCM) to analyze cell cycle kinetics, and observed that OP-A strongly inhibits U373-MG cell cycle progression. Indeed, after $24 \mathrm{~h}$, we observed an increase in the number of cells in $\mathrm{G}_{0} / \mathrm{G}_{1}$ phase from $50 \%$ for the control to $74 \%$ for the OP-A-treated cells $(P<0.01)$, whereas, after $72 \mathrm{~h}$, OP-A induced a sharp increase in the number of cells in S phase from $24 \%$ (control) to $55 \%$ $(P<0.01)$ (Figure 2g).

OP-A induces morphological changes and inhibits the migration of GBM cells. As shown in Figure 2a, the U373MG cells exhibited an elongated morphology (a-arrows) after treatment with OP-A, suggesting cytoskeletal changes. Fluorescence microscopy analyses showed that the control U373-MG cells possessed a highly developed actin cytoskeleton with numerous stress fibers (Figure 3al). Immediately after $6 \mathrm{~h}$ of treatment with $1 \mu \mathrm{M}$ OP-A, we observed distinct changes in the U373-MG cell morphology and the reorganization of actin filaments. The number of small, shrunken cells with intensely polymerized actin (green a

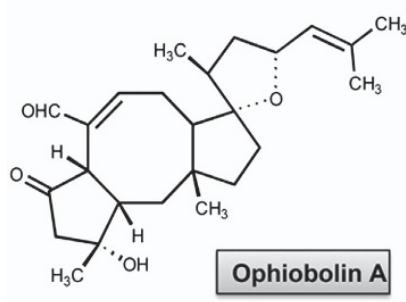

b

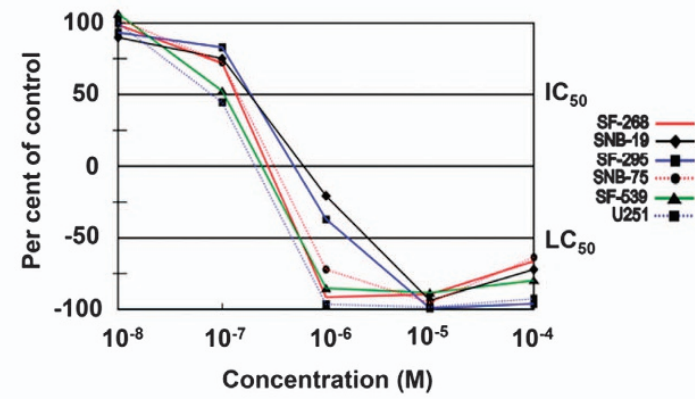

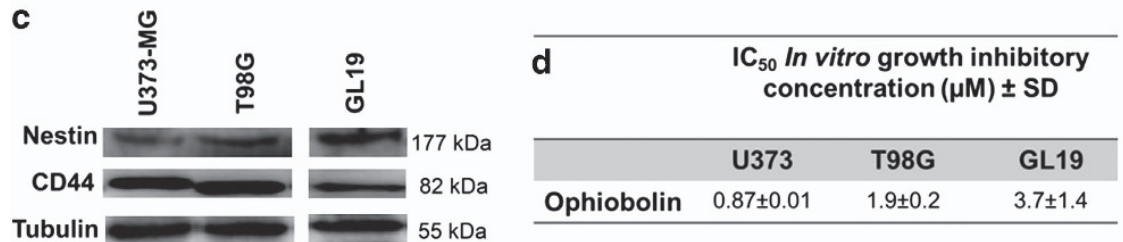

Figure 1 Ophiobolin A has anticancer activity in GBM cells. (a) Structure of ophiobolin A. (b) NCl five-dose screen of ophiobolin A on four human GBM (SF-268, SNB-19, SF-295, SNB-75 and U251) cell lines and one human gliosarcoma (SF-539) cell line after $48 \mathrm{~h}$ of treatment. The response parameters IC50 (50\% growth inhibition) and LC50 (50\% lethal concentration) are shown on the graph. (c) Expression of stem cells markers such as CD44 and nestin in U373-MG, T98G and GL19 cells determined by immunoblot. (d) Growth inhibitory effects of ophiobolin A on the U373-MG, T98G and GL19 GBM cell lines as determined using the MTT assay. The data represent the mean values \pm S.D. (two independent experiments, each condition performed in sextuplicate) 
a
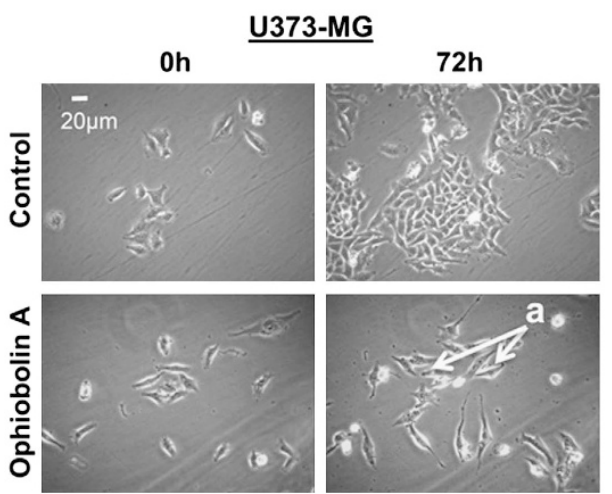

b
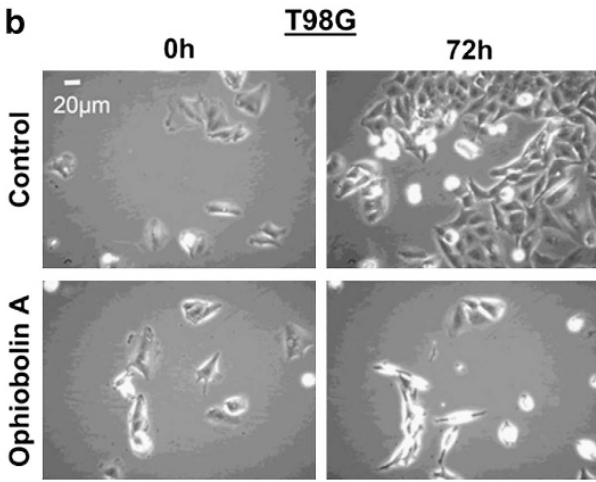

c
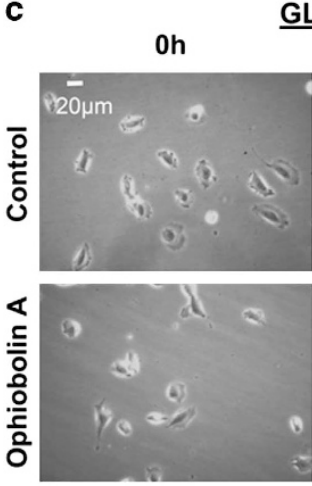

$\underline{\text { GL19 }}$

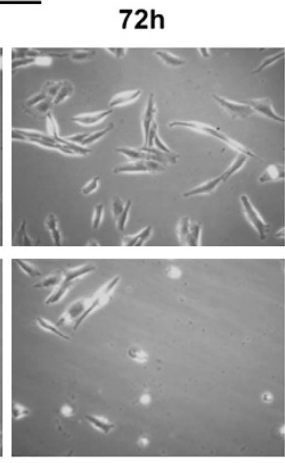

d

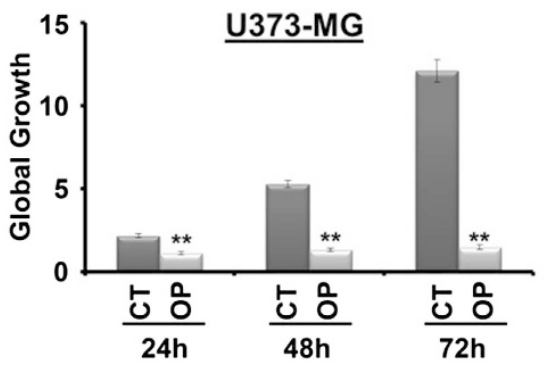

e
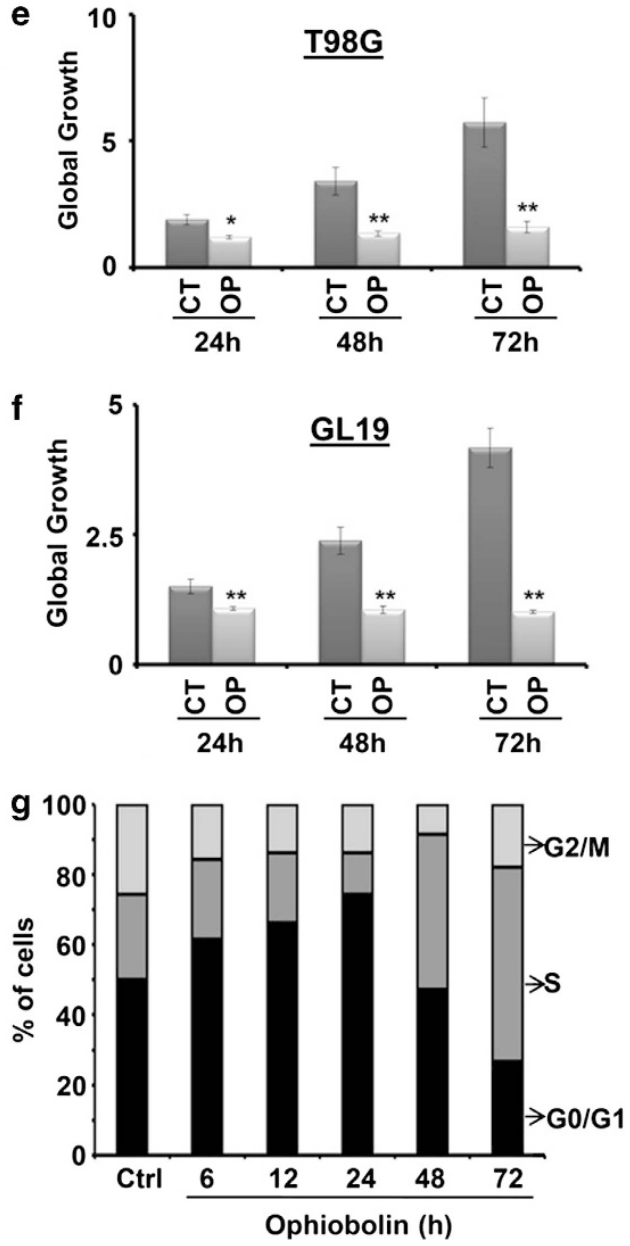

Figure 2 Ophiobolin A (OP) inhibits the proliferation of GBM cells. (a-c) Computer-assisted phase contrast microscopy images of U373-MG, T98G and GL19 GBM cells showing the antiproliferative effects induced by OP at 1,2 and $4 \mu \mathrm{M}\left(\sim \mathrm{IC} \mathrm{C}_{50}\right)$, respectively. The a-arrows represent the elongation of U373-MG cells treated with $1 \mu \mathrm{M}$ OP for $72 \mathrm{~h}$. (d-f) In vitro global growth (GG) of OP-treated GBM cells compared with their control counterparts. The GGs were determined as described in the Materials and Methods. $\mathrm{OP}$ treatment resulted in slower growth kinetics rates over time. The data represent the mean values \pm S.E.M. (two independent experiments, each performed in triplicate; *denotes $P<0.05$; **denotes $P<0.01$ ). (g) Flow cytometry analysis (IP staining, $n=6$ ) of U373-MG cells to analyze the cell cycle distribution. $1 \mu \mathrm{M}$ OP strongly slowed cell cycle progression

fluorescence) and normal globular actin (red fluorescence) increased (Figure 3all). After $30 \mathrm{~h}$ of incubation, OP-A caused a significant increase in the number of cells without (or with very low) fibrillar actin fluorescence signals, but with strongly labeled globular actin (Figure 3alll and IV). Because the organization of the actin cytoskeleton is sensitive to changes in calcium, we determined the intracellular calcium concentrations in U373-MG cells with and without OP-A treatment. Our data show that the observed increases in the amount of F-actin in OP-A-treated U373-MG cells at $6 \mathrm{~h}$
(Figure 3a) correlated with the increased intracellular calcium concentration (Figure 3b). Furthermore, the dynamics of the actin cytoskeleton are critical for cell motility, ${ }^{15}$ and our data accordingly show that OP-A $(1 \mu \mathrm{M})$ decreased the two-dimensional-migration potential of U373-MG GBM cells over a $24-\mathrm{h}$ period $(P<0.001)$ (Figures $3 c$ and $d$ ).

OP-A induces cytoplasmic vacuolization and mitochondrial damage. U373-MG, T98G and GL19 cells were 
a
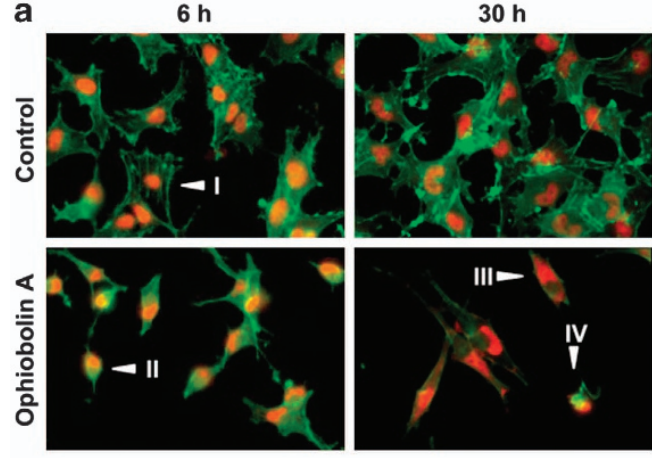

b

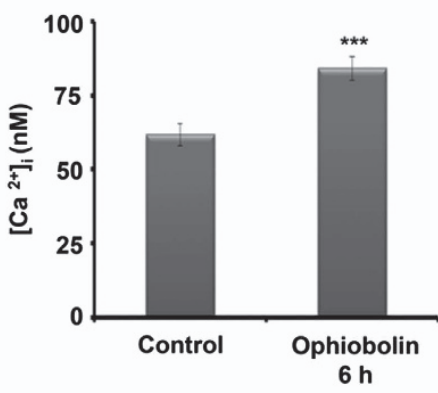

C

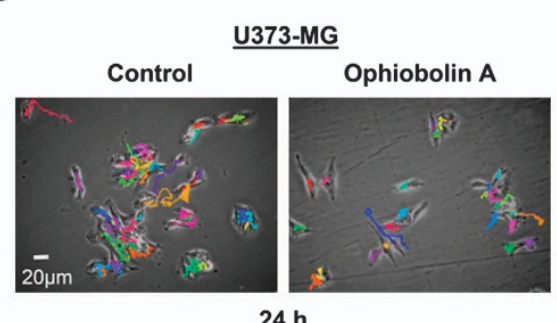

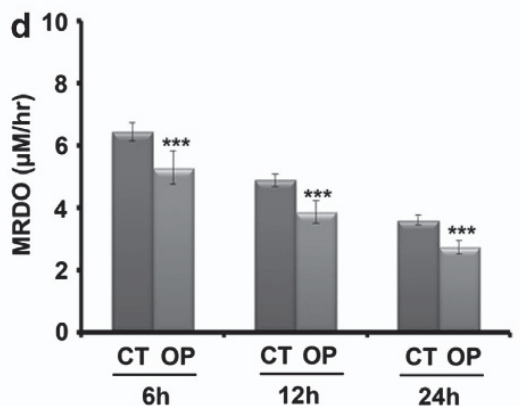

Figure 3 Ophiobolin A (OP) induces morphological changes and inhibits the migration of U373-MG GBM cells. (a) Fluorescence microscopy was employed to visualize the fibrillar (polymerized) actin in green and the globular (unpolymerized) actin in red. The effects of $1 \mu \mathrm{M}$ OP were assessed at 2, 6 and $30 \mathrm{~h}$. (I) Cells with highly developed actin cytoskeletons with numerous stress fibers; (II) small, shrunken cells with intensely polymerized actin and globular actin; (III) disintegrated cells with very low fibrillar actin fluorescence signals and (IV) cells strongly labeled for globular actin. (b) Measurement of the intracellular calcium concentration using the FURA-2 fluorescence ratio. The cytosolic free $\mathrm{Ca}^{2+}$ concentrations in control and OP-treated $(1 \mu \mathrm{M})$ U373-MG cells were $62 \pm 4 \mathrm{nmol} / \mathrm{l}(n=41)$ and $84 \pm 4 \mathrm{nmol} / \mathrm{l}\left(n=77\right.$; ${ }^{* *}$ denotes $\left.P<0.001\right)$, respectively (c) The motility of individual cells treated with $1 \mu \mathrm{M}$ OP was quantified by establishing the trajectory of each cell centroid and by quantifying the MRDO variable (the maximum distance covered by a cell normalized by the observation time, expressed in $\mu \mathrm{m} / \mathrm{h}$ ). (d) The distribution of MRDO values obtained for U373-MG cells treated with $1 \mu \mathrm{M}$ OP for 6,12 and $24 \mathrm{~h}(n=82)$ compared with the MRDO values for untreated cells $\left(n=141\right.$; ${ }^{* \star *}$ denotes $\left.P<0.001\right)$. OP decreased the two-dimensional-migration of U373-MG GBM cells over a 24-h period

exposed to OP-A for $72 \mathrm{~h}$ and were assessed by phase contrast microscopy (Figures 2a-c). The images in Figure 4a indicate that OP-A $(1 \mu \mathrm{M})$ caused a dramatic increase in vacuolization processes in U373-MG cells after $6 \mathrm{~h}$ of exposure. We noticed that these vacuoles were ejected from the cells over time (Figure 4a, white arrows) and similar results were also observed with T98G and GL19 (data not shown). To further characterize the morphological dynamics of the cytoplasmic vacuolization process, experiments were performed at a single living cell level using MitoTracker and ER-Tracker stains (Figures 4b-d). The mitochondrial and ER fluorescence in OP-A-treated $\left(\mathrm{IC}_{50}\right) \mathrm{GBM}$ cells indicated that the OP-A-induced vacuoles originated from both the mitochondria and the ER (Figures $4 b$ and $c$ ). In addition, as is seen in Figure $4 d$, the analyses revealed that cytoplasmic vacuolization was at least partly due to mitochondrial swelling caused by OP-A exposure. Indeed, OP-A-treated $\left(\mathrm{IC}_{50}\right)$ GBM cells possessed many enlarged green fluorescent mitochondria, in contrast to control cells, which contained small green mitochondria with a fine fibrous distribution (Figure 4d). Cytoplasmic vacuolization and enlarged mitochondria have been reported to be the typical features of paraptosis. ${ }^{4}$ Moreover, the number of cells with high levels of red staining (acridine orange $(A O)$ staining) did not increase, indicating that these vacuole-like organelles, which appeared to interact directly with the plasmalemma, were not acidic and thus not autophagic after $\left(\mathrm{IC}_{50}\right)$ OP-A treatment (illustrated in Figures $5 a$ and $b$ ). We also observed that the number of cells with high levels of green staining (AO staining) did not increase, indicating that OP-A did not induce membrane permeabilization of lysosomes (data not shown).

OP-A induces paraptosis-like cell death. The abovementioned findings prompted us to further investigate whether the anticancer effects of OP-A in GBM cancer cells share other characteristics with paraptosis. First, using trypan blue staining, we demonstrated that OP-A induced the death of $\sim 45 \%$ of GBM cells after $72 \mathrm{~h}(P<0.001)$ (Figure $5 \mathrm{c}$ and d). However, as shown in Figure 6a, FCMrelated TUNEL (terminal deoxynucleotidyltransferase dUTP nick end labeling) analysis demonstrated that fewer than $30 \%$ (after $48 \mathrm{~h}$, data for $72 \mathrm{~h}$ not shown) of U373-MG cells treated with $1 \mu \mathrm{M}$ OP-A underwent DNA degradation processes. To confirm that OP-A-induced cell death does not involve apoptosis, we used annexin $\mathrm{V}$ staining assay to assess the extent of phosphatidyl-serine externalization. We found that there is no change in the percentages of annexin V-positive cells between control and OP-A-treated $\left(\mathrm{IC}_{50}\right)$ U373-MG, T98G and GL19 cells after $72 \mathrm{~h}$ (data not shown). Then, to determine whether OP-A induced necrotic cell death, we examined the effect of OP-A on the disruption of 
7h

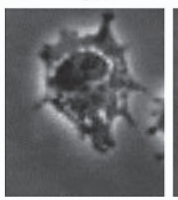

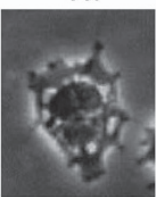

$8 h$

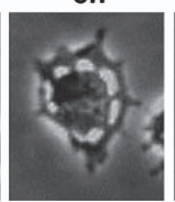

9h

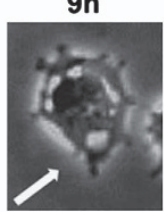

$10 \mathrm{~h}$

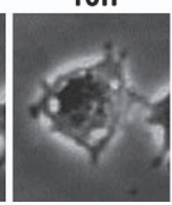

11h

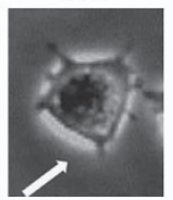

b
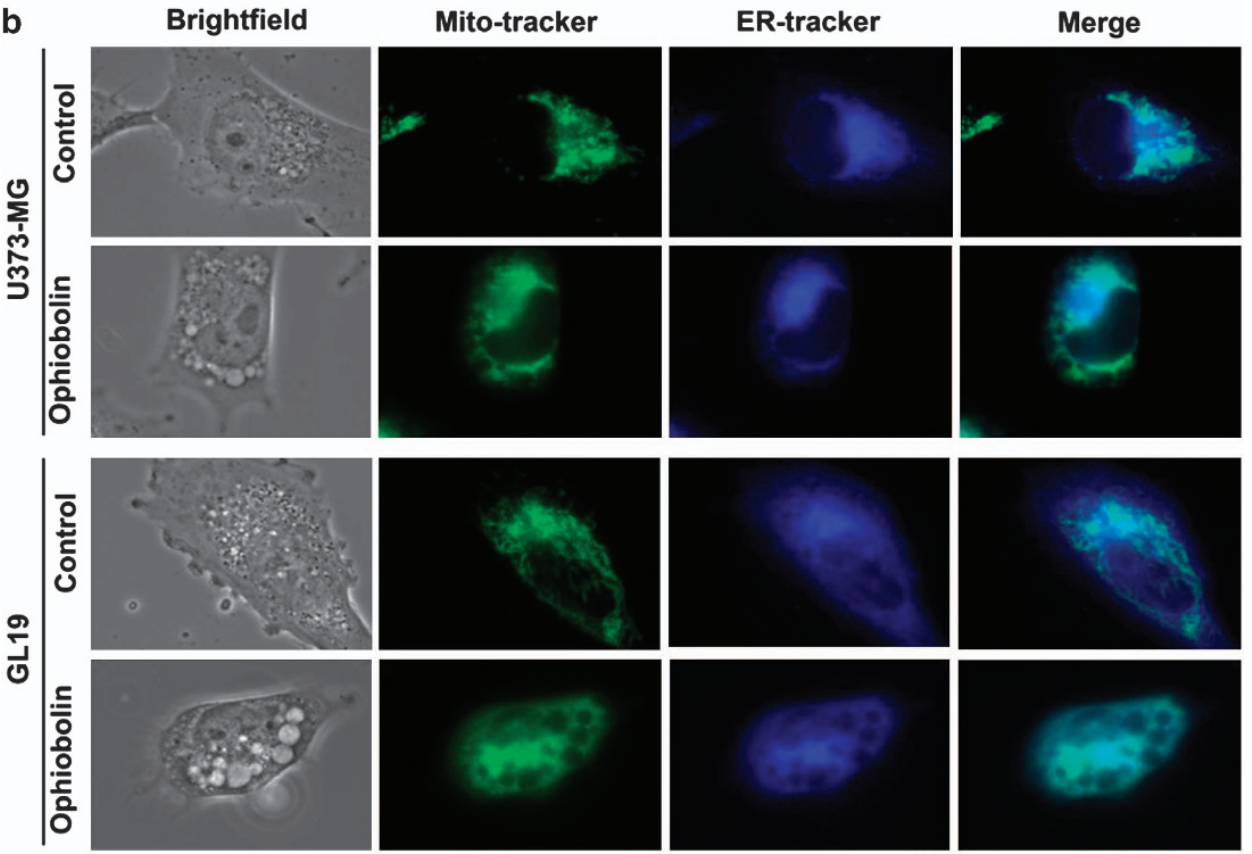

C

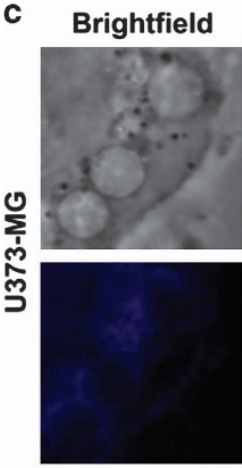

ER-tracker

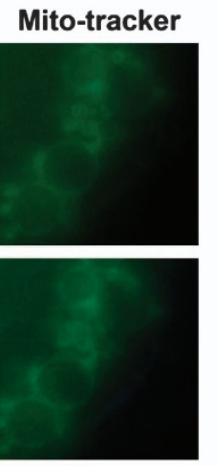

Merge d

U373-MG
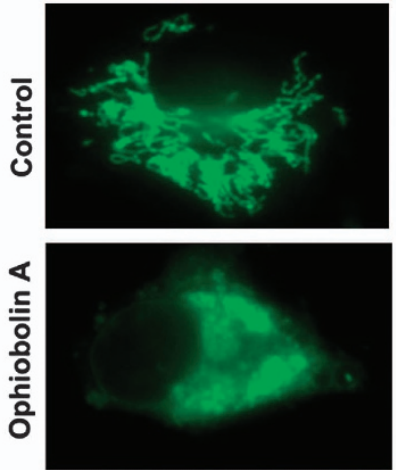

GL19
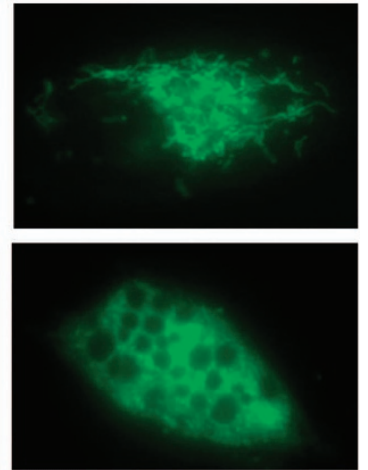

Figure 4 Ophiobolin A induces cytoplasmic vacuolization and mitochondrial swelling. (a) Computer-assisted phase contrast microscopy image of the cytoplasmic vacuolization induced by ophiobolin A at $1 \mu \mathrm{M}$ in human U373-MG GBM cells. Ophiobolin A caused a dramatic increase in vacuolization in GBM cells after $6 \mathrm{~h}$ of exposure. We observed that these vacuoles were ejected from the cell over time (white arrows). (b) ER-Tracker- and MitoTracker-labeled living U373-MG and GL19 GBM cells were exposed to culture media alone (control) or with 1 and $4 \mu \mathrm{M}$ ophiobolin A for $6 \mathrm{~h}$, respectively. Ophiobolin A-induced vacuoles originated from both the mitochondria and the ER. (c) High-magnification fluorescence images of U373-MG cells treated for $6 \mathrm{~h}$ with $1 \mu \mathrm{M}$ ophiobolin A and stained with ER-Tracker and MitoTracker. (d) Typical fluorescence images of mitochondria at 0 and $6 \mathrm{~h}$ after ophiobolin treatment. Ophiobolin A-treated U373-MG and GL19 cells possessed many enlarged green fluorescent mitochondria, in contrast to control cells, which contained small green mitochondria with a fine fibrous distribution

the cell membrane by PI staining. The data obtained also ruled out necrosis as a potential mode of OP-A-induced cell death because the percentages of PI-positive cells were similar between control and OP-A-treated GBM cells after $72 \mathrm{~h}$ (data not shown). These last results were confirmed in U373-MG by immunoblot analyses, which showed that treatment with OP-A $(1 \mu \mathrm{M})$ did not induce poly(ADP-ribose) polymerase (PARP) cleavage, suggesting that the cell death was independent of caspases (Figure 6b), unlike the cell death induced by the positive control 4IBP, a sigma 1 receptor agonist, which induced PARP cleavage (Figure 6b). ${ }^{16}$

In another set of experiments, we quantified senescence based on the enlarged, flattened morphology and vacuolization, ${ }^{17}$ as well as using a typical marker of senescence in human cells, senescence-associated $\beta$-galactosidase (SA- $\beta$-gal). ${ }^{18}$ A549 NSCLC cells treated with $100 \mathrm{nM}$ 


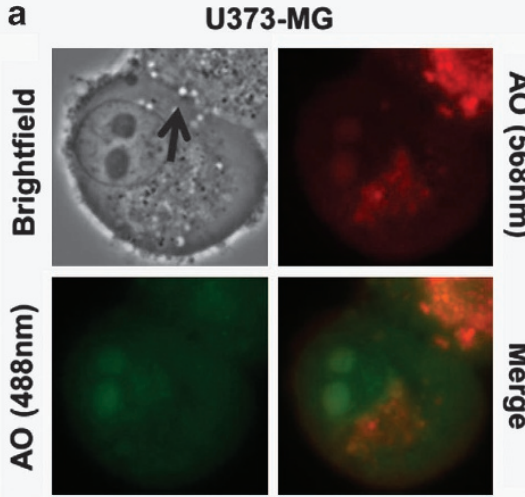

Ophiobolin 6h b $\quad$ GL19
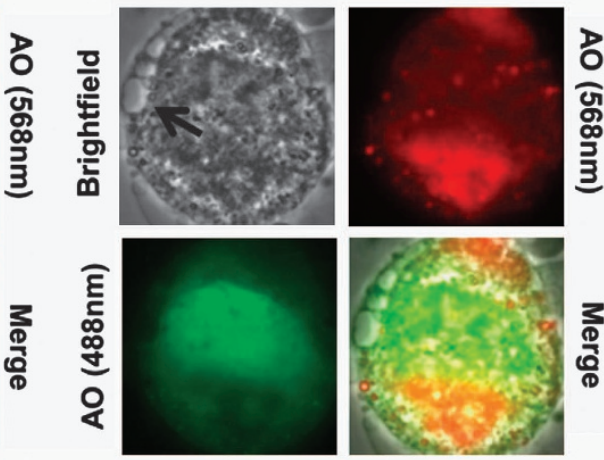

Ophiobolin 6h

c
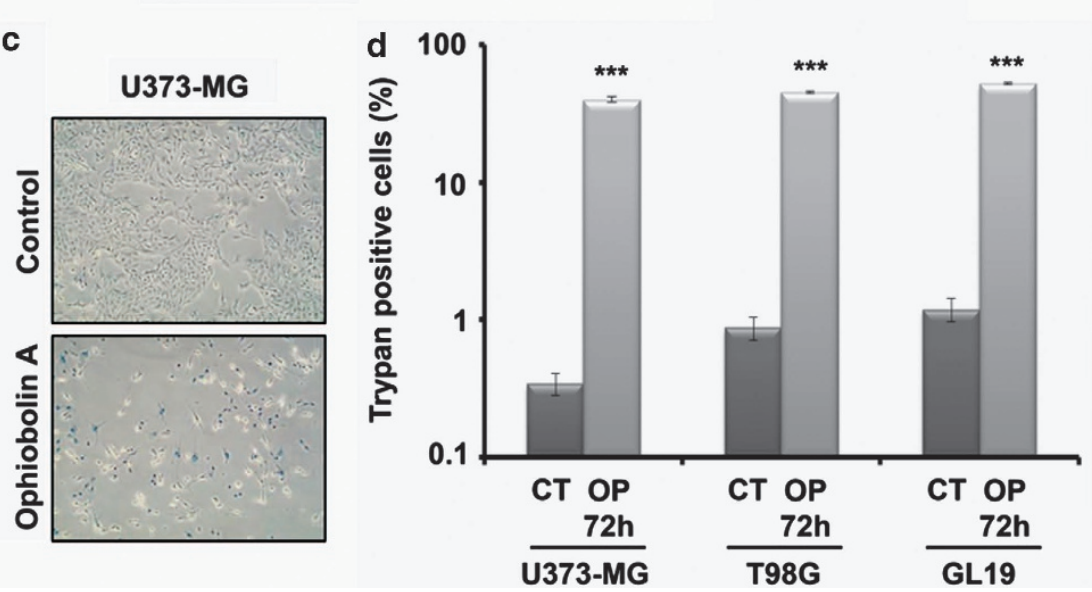

Figure 5 Ophiobolin A (OP) induces a type of cytoplasmic vacuoles which are not autophagic and induces cell death in GBM cells. (a and $\mathbf{b})$ Acridine orange (AO)-labeled U373-MG and GL19 GBM cells were exposed to 1 and $4 \mu \mathrm{M}$ OP for $6 \mathrm{~h}$, respectively. The cytoplasmic vacuoles induced by OP (Figure 4) are not acidic. Moreover, OP did not induce membrane permeabilization of lysosomes. (c) Images of U373-MG cells that were either untreated or treated with $1 \mu \mathrm{M}$ OP for $72 \mathrm{~h}$; the cells were stained with trypan blue, and dead cells appear blue. (d) Cell viability was assessed after $72 \mathrm{~h}$ of $\mathrm{OP}$ treatment $\left(\mathrm{IC}_{50}\right)$ and subsequent trypan blue staining. The percentages of dead cells among the control and OP-treated GBM cells were $0.34 \pm 0.06$ and $40 \pm 2$ (U373-MG), $0.9 \pm 0.2$ and $45.0 \pm 0.9$ (T98G), $1.2 \pm 0.2$ and $52 \pm 1$ (GL19), respectively (two independent experiments, each performed in triplicate; ${ }^{* * *}$ denotes $\left.P<0.001\right)$

doxorubicin were used as a positive control. ${ }^{19}$ The data presented in Figure 6c show that doxorubicin indeed induced a markedly increased level of senescence processes in A549 NSCLC cells, in contrast to OP-A, which did not produce similar effects in U373-MG GBM cells. Moreover, the pretreatment of U373-MG cells with $0.25 \mu \mathrm{g} / \mathrm{ml}$ cycloheximide $(\mathrm{CHX})$ effectively decreased the level of OP-induced cell death $(P<0.001$; Figure $6 \mathrm{~d})$, suggesting that protein synthesis is required for this process, another characteristic of paraptosis. ${ }^{4}$

BKCa channels are found in the organelles involved in paraptosis. The OP-A-induced increase in the intracellular calcium level (Figure $3 \mathrm{~b}$ ) then prompted us to determine whether some types of ion channels, such as $\mathrm{Ca}^{2+}$-activated $\mathrm{K}^{+}(\mathrm{KCa})$ channels, could be potential targets for the OP-Amediated anticancer effects observed in human U373-MG GBM cells. Indeed, the inhibition of proton extrusion by OP-A in plant cells was found to be because of an effect on the permeability of the plasma membrane to potassium. ${ }^{9}$ Therefore, we tested the effects of OP-A on KCa channels, specifically $\mathrm{BKCa}$ channels, because these channels are involved in paraptosis. ${ }^{5}$ We hypothesized that the modulation of BKCa channel activity by OP-A in GBM cells would disrupt the normal internal ion homeostasis and the osmotic balance, initiating the swelling process observed in paraptosis. ${ }^{5}$ Using the immunofluorescence pseudo-confocal microscopy with a BKCa $\alpha$-subunit-specific antibody, we identified the sub-cellular localization of the BKCa channels in control U373-MG GBM cells. The top and bottom panels in Figure $7 \mathrm{a}$ show that $\mathrm{BKCa}$ channels were found at several membrane locations (the mitochondria, the ER and the nucleus) within the cell as well as along the edges of the cell membrane (Figure 7a). In colocalization studies, the mitochondria were stained with a specific green stain (MitoTracker Green) in combination with the red fluorescent antiBKCa channel antibody. The overlay Figure shows yellow staining at many sites within the cells where mitochondria are present (Figure 7a). A similar approach was used to stain the ER with a green fluorescent mouse anti-GRP78 antibody and the anti-BKCa channel antibody. The BKCa channels and the ER appear to colocalize to a greater extent than did the BKCa channels and mitochondria (Figure 7a). 
a
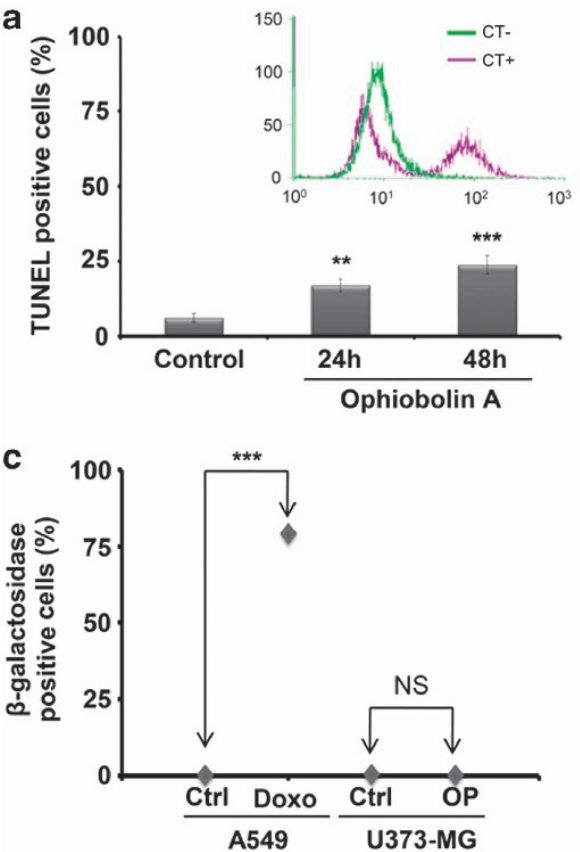

b
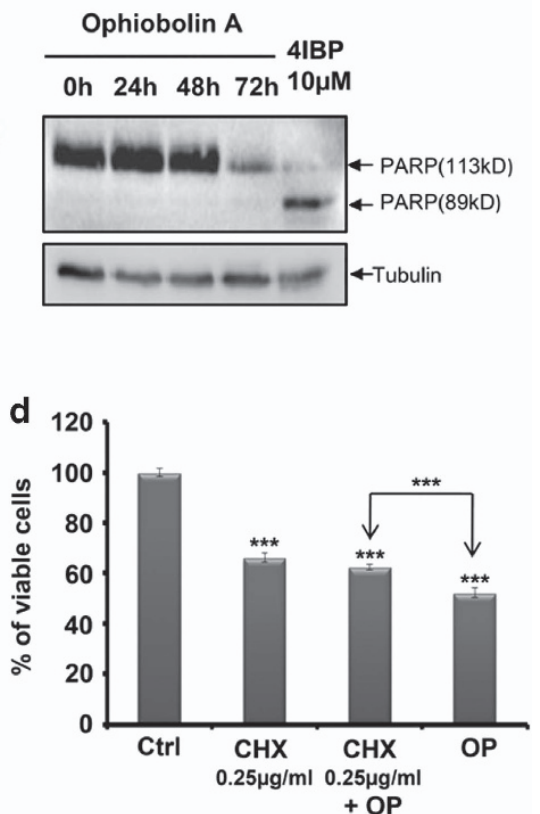

Figure 6 Ophiobolin A (OP) induces paraptosis-like cell death in U373-MG glioma cells. (a) Flow cytometry (FCM)-related analyses (TUNEL) of the percentages of apoptotic U373-MG GBM cells that were treated for 24 and $48 \mathrm{~h}$ with $1 \mu \mathrm{M}$ OP (two independent experiments, each performed in triplicate; ${ }^{\star *}$ denotes $P<0.01$; ${ }^{\star \star \star}$ denotes $P<0.001$ ). The positive and negative controls were provided by the manufacturer of the TUNEL kit and are presented above the graph. (b) U373-MG cells were treated with $1 \mu \mathrm{M}$ OP for $0,24,48$ and $72 \mathrm{~h}$. Total cell lysates were resolved on SDS-PAGE gels and immunoblotted with an anti-PARP antibody. Equal loading was verified by anti-tubulin immunoblotting (lower blot). The data are representative of at least two different experiments; 4IBP-treated U373-MG cells were used as a positive control for the cleavage of PARP. (c) The percentages of $\beta$-gal-positive cells determined by counting 10 random fields under a phase contrast microscope (two independent experiments, each performed in triplicate; ${ }^{* * *}$ denotes $P<0.001$ ). Doxorubicin induced a marked increase in senescence processes in A549 NSCLC cells, whereas OP did not induce senescence in U373-MG GBM cells. (d) Effects of $0.25 \mu \mathrm{g} / \mathrm{ml}$ cycloheximide (CHX) on cell death. Cells were exposed to OP $(1 \mu \mathrm{M})$ for $24 \mathrm{~h}$ with or without $\mathrm{CHX}$ and were analyzed with the MTT colorimetric assay to determine the global growth levels under each experimental condition $\left(n=12\right.$; ${ }^{* *}$ denotes $\left.P<0.001\right)$. The pretreatment of U373MG cells with $\mathrm{CHX}$ decreased the level of OP-induced cell death

GBM cells possess functional BKCa channels. The expression of BKCa channels in U373-MG, T98G and GL19 cells was verified using immunoblot (Figure $7 \mathrm{~b}$ ). The use of the whole-cell patch-clamp technique further demonstrated that the U373-MG cells had functional BKCa channels in the plasma membrane. The presence of functional BKCa channels was confirmed using iberiotoxin, a selective inhibitor of these channels (Figure 7c). ${ }^{20}$ These results are consistent with the published data, concerning the presence of functional BKCa channels in glioma cell lines. ${ }^{21}$

OP-A decreases BKCa channel activity. The various data reported above indicate that $\mathrm{BKCa}$ channels may be associated with paraptosis, as also suggested by reports in the literature, ${ }^{5}$ and these results prompted us to test the effects of OP-A on the potassium current of U373-MG cells using a patch-clamp approach. Our results showed that $1 \mu \mathrm{M}$ OP-A significantly reduced, by $20 \%$, the amplitude of the outward currents of U373-MG cells at $+70 \mathrm{mV}$ (Figure 7e). It is important to note that $1 \mathrm{mM}$ tetraethylammonium, an inhibitor of $\mathrm{BKCa}$ channel at this concentration, did not produce a significant additive inhibitory effect (Figures 7e and $\mathrm{f}$ ). The inhibition observed in presence of OP-A increased to $\sim 50 \%$ at $10 \mu \mathrm{M}$ (Figure $7 \mathrm{f}$ ). Altogether, these data suggest that the OP-A-induced in vitro anticancer effects are because of, at least in part, the modulation of ion transport across the plasma membrane in U373-MG cells, a feature that could be attributed to the modulation of BKCa channels.

\section{Discussion}

GBM is the most common adult primary brain cancer and it remains the deadliest of all forms of brain tumors despite the many clinical trials that have attempted to improve the dismal outcomes. Complete resection remains virtually impossible due to the invasive nature of GBM cells into the brain parenchyma. In addition, the intrinsic resistance of GBM cells to radiation- and chemotherapy-induced apoptosis contributes to treatment failure. ${ }^{1,2}$ Therefore, it is essential to find novel therapeutic agents that can overcome this intrinsic resistance of GBM cells to apoptosis.

The evaluation of biopsy tissues from patients with malignant gliomas revealed significant expression of $\mathrm{BKCa}$ channel proteins, and studies of human glioma cell lines have established that functional BKCa channels, the predominant $\mathrm{K}^{+}$channel type, are highly expressed in these cells, ${ }^{22}$ as we observed with U373-MG, T98G and GL19 GBM cells (Figures $7 \mathrm{a}$ and $\mathrm{b})$. In the current study, OP-A, a phytotoxic sesterterpenoid of fungal origin, was shown to be an inhibitor 
a

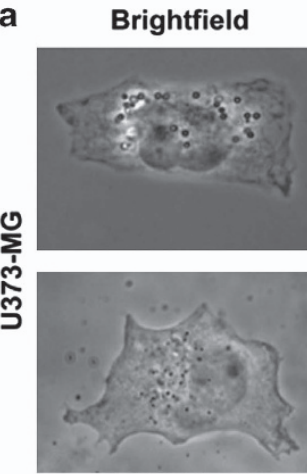

Brightfield

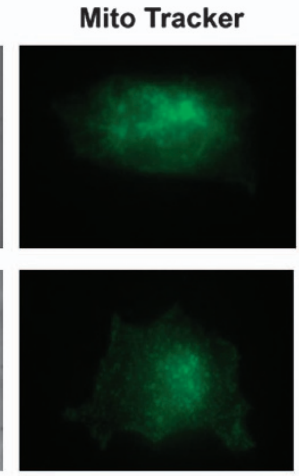

GRP78

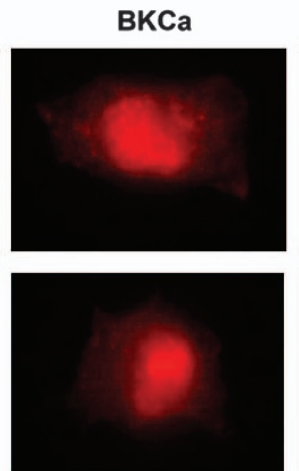

BKCa
Co-localization
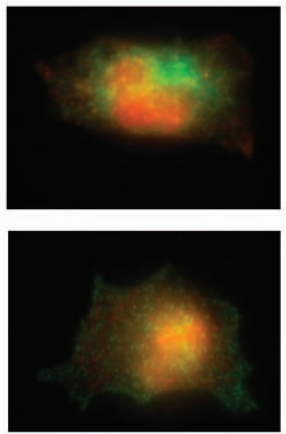

Co-localization b

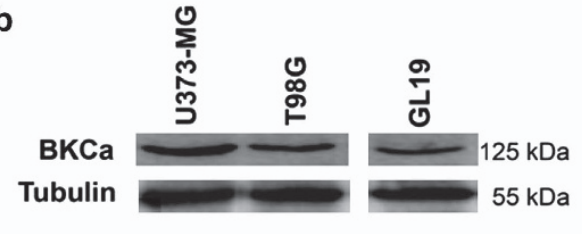

C

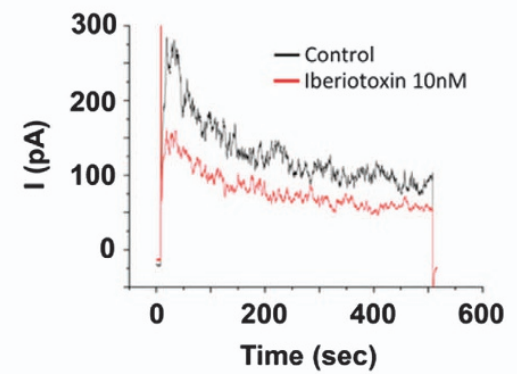

d
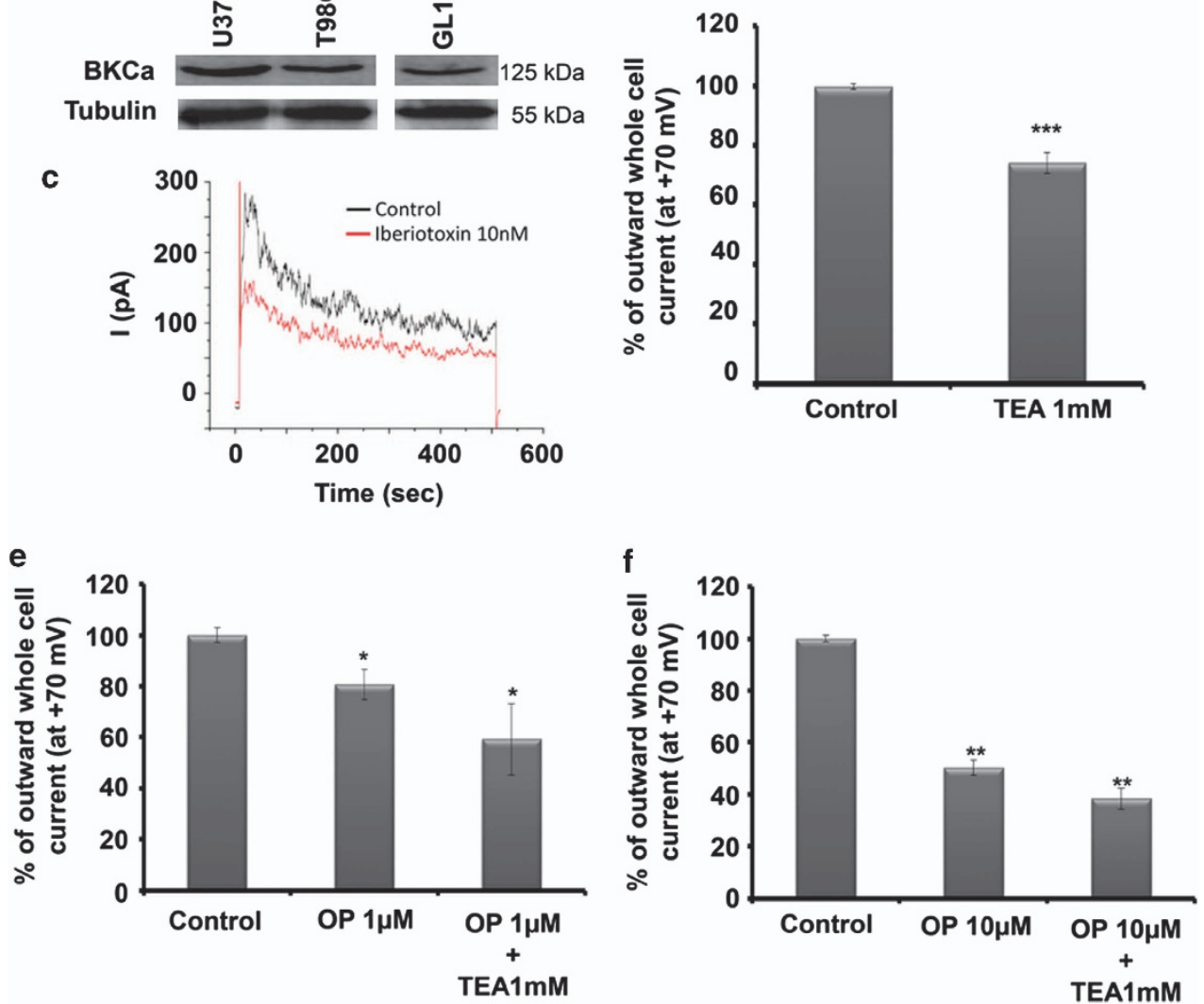

Figure 7 Ophiobolin A (OP) decreases BKCa channel activity. (a) U373-MG cells possess BKCa channels on the cell membrane and within the mitochondria and ER. The top panel shows U373-MG GBM cells stained with MitoTracker or an anti- $\alpha$-subunit-BKCa channel antibody. The bottom panel shows images for another preparation of the U373-MG cells stained with anti-GRP78 or anti- $\alpha$-subunit-BKCa channel antibodies. The merged yellow figures on the right represent one plane in which colocalization was present. (b) Expression of $\alpha$-subunit-BKCa channels in U373-MG, T98G and GL19 cells as determined by immunoblot. (c) U373-MG cells possess functional BKCa channels as demonstrated by the patch-clamp technique with a selective inhibitor of this channel, iberiotoxin. An example of whole-cell current recordings in the absence (control) or presence of $10 \mathrm{nM}$ iberiotoxin. (d-f) Outward whole-cell current (in percent of control condition) elicited by a depolarizing pulse from a holding potential of $-70 \mathrm{mV}$ to $+70 \mathrm{mV}$ under control conditions or in the presence of $1 \mathrm{mM}$ tetraethylammonium (TEA) (d), $1 \mu \mathrm{M} \mathrm{OP}(\mathbf{e}), 10 \mu \mathrm{M} \mathrm{OP}$ (f) or OP with $1 \mathrm{mM}$ TEA. The data represent the mean values \pm S.E.M. (two independent experiments, each performed in triplicate; ${ }^{*}$ denotes $P<0.05$; ${ }^{* *}$ denotes $P<0.01$; ${ }^{* * *}$ denotes $P<0.001$ ).

of BKCa channels in U373-MG GBM cells. We demonstrated that the blockade of BKCa channels with OP-A results in decreased cell proliferation and migration and an increased level of non-apoptotic cell death. Preliminary in vivo data revealed that chronic administrations of $10 \mathrm{mg} / \mathrm{kg}$ of OP-A led to significant increases in the survival of mice bearing lung pseudometastases from the B16F10 melanoma (article in submission).

Weaver et al. ${ }^{22}$ showed that iberiotoxin, a selective inhibitor of BKCa channels, increases the percentage of glioma cells in $S$ phase, as shown for OP-A, whereupon cells undergo cell death. Iberiotoxin interacts with specific residues in the outer 
vestibules of the BKCa channel to physically occlude the pore. ${ }^{23}$ The BKCa channel consists of two dissimilar subunits, $\alpha$ and $\beta$. The $\alpha$ subunit is a member of the human slo KCa gene family, which forms the ion conduction pore. ${ }^{24,25}$ There are four types of $\beta$-subunits, $\beta 1-\beta 4$, and they have tissue-specific distributions. These subunits act as receptors for drugs, modify drug pharmacological properties and are known to affect toxin binding. ${ }^{24,25}$ However, the mode of action of OP-A does not seem to be the same as that of iberiotoxin. Indeed, we tested OP-A on human embryonic kidney 293T cells expressing only $\alpha$-hslo, and we did not observe the reduction in the amplitude of the outward currents in these cells, suggesting that the $\beta$-subunit is involved in the reduced amplitude. The loop of the $\beta$-subunit could in fact contribute to the stabilization of the OP-A-bound state, either by a direct interaction with OP-A or through an allosteric effect on the $\alpha$-subunit. McManus et al. ${ }^{26}$ have previously shown that the agonist activity of glycosylated triterpenes, such as dehydrosoyasaponin I, requires the presence of the $\beta$-subunit.

$\mathrm{BKCa}$ channels have an important role in glioma cell migration. ${ }^{27}$ Indeed, after an increase in the $\mathrm{Ca}^{2+}$ concentration, the $\mathrm{BKCa}$ and $\mathrm{CIC}-3$ channels are activated, and release $\mathrm{K}^{+}$and $\mathrm{Cl}^{-}$ions together with water, causing the rapid shrinkage of the cells, which facilitates the invasion of the cells into the narrow extracellular brain spaces. ${ }^{27}$ Moreover, calcium is a prominent regulator of cell motility that can exert multiple effects on the structure and dynamics of the actin cytoskeleton. ${ }^{28}$ Consequently, the blockade of BKCa channels and the resulting increase in the $\left(\mathrm{Ca}^{2+}\right)_{i}$ caused by OP-A could explain, at least in part, the decrease in cell migration, as previously shown with iberiotoxin, a specific inhibitor of this channel. ${ }^{29}$

Hoa et al..$^{5}$ have previously shown that paraptosis is related to the modification of BKCa channel activity. Indeed, these authors hypothesized that the opening of $\mathrm{BKCa}$ channels gives rise to the expulsion of $\mathrm{K}^{+}$in exchange for $\mathrm{Na}^{+}$required to maintain electroneutrality of the cell. The admission of $\mathrm{Na}^{+}$ leads to the uptake of water, producing the observed cellular swelling and vacuolization that occurs when the ER and mitochondria swell. The proposed mechanism through which OP-A causes death in GBM cells by paraptosis is presented in Figure 8. We propose (Figure 8) that the closing of the $\mathrm{BKCa}$ channels (Figure 7) in the cell membrane, the ER and the mitochondria obstructs the expulsion of $\mathrm{K}^{+}$. The retention of $\mathrm{K}^{+}$leads to a rapid increase in the water content to maintain cell homeostasis, producing the observed cellular swelling and the formation of cytoplasmic vacuoles (Figure 4). As the compensatory mechanism, the cells try to expel these vacuoles by exocytosis. In the second step, the consecutive depolarization of the membrane most likely causes L-type voltage-dependent calcium channels activation, causing a progressive increase in the $\left(\mathrm{Ca}^{2+}\right)_{\mathrm{i}}$, as was detected in U373MG cells after only $6 \mathrm{~h}$ of treatment with $1 \mu \mathrm{M}$ OP-A (Figure $3 b$ ). The coassembly of these channels with $\mathrm{BKCa}$ channels has been demonstrated in rat brains. ${ }^{30}$ One nonexclusive possibility is that there is an increase in the $\left(\mathrm{Ca}^{2+}\right)_{i}$ involving $\mathrm{IP}_{3} /$ ryanodine receptors, resulting from compensatory mechanisms of the organelles that allow them to maintain homeostasis. ${ }^{31}$ A long-term increase in the concentration of calcium and intracellular electrolytes could be the causes of

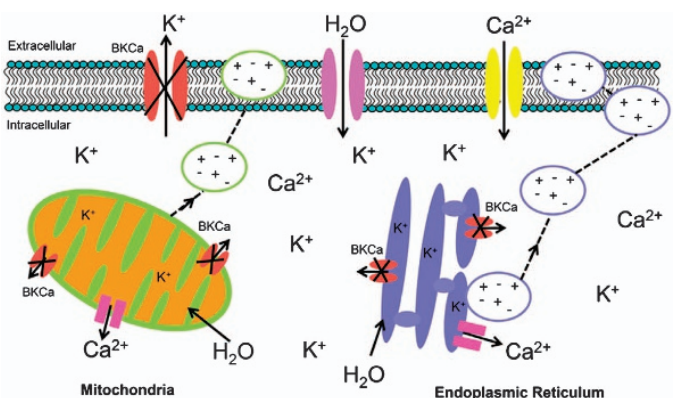

Figure 8 Proposed mechanism by which ophiobolin A induces paraptosis in GBM cells. Ophiobolin A blocks the BKCa channels present on the cell membrane, mitochondria and ER. The inhibition of BKCa induces an increase in the intracellular $\mathrm{K}^{+}$concentration. To maintain homeostasis, water enters the cell, inducing first swelling and then vacuolization. In order to compensate the electrolyte disorders because of the excess of the maintenance of homeostasis, these vacuoles could then be expelled out of the cell by exocytosis. The consecutive depolarization of the membrane most likely opens the calcium channels present in the membrane, causing a progressive increase in the $\left(\mathrm{Ca}^{2+}\right)_{\mathrm{i}}$. Another possibility is that this increase in the $\left(\mathrm{Ca}^{2+}\right)_{\text {i }}$ could result from the compensatory mechanisms that the organelles (mitochondria and ER) use to maintain homeostasis; these mechanisms could involve $\mathrm{IP}_{3}$ /ryanodine receptors

the paraptotic cell death in GBM cells observed in the current study.

In conclusion, the current report highlights the potential use of OP-A to overcome the intrinsic resistance of glioblastoma cells to proapoptotic stimuli through BKCa channel-mediated induction of paraptosis. Further experiments are in progress to evaluate the proposed mechanism in detail.

\section{Materials and Methods}

Established cell lines, primoculture and OP-A. The human GBM cell lines U373-MG (ATCC code HTB-17) and T98G (ATCC code CRL1690) were obtained from the American Type Culture Collection (ATCC, Manassas, VA, USA) and maintained in our laboratory as described previously. ${ }^{32}$ One distinct primary GBM cell culture of astrocytic origin (designated GL19 in the present study) was established at the Department of Neurosurgery, Wagner Jauregg Hospital, Linz as previously described. ${ }^{33}$ Briefly, surgical specimens of histocytologically confirmed GBM lesions from various sites were blended mechanically and transferred into culture flasks containing growth medium (RPMI 1640, 20\% fetal calf serum, $1 \%$ glutamine, $1 \%$ penicillin/streptomycin; PAA Laboratories, Linz, Austria). After passage 3 , the cells were cultured in growth medium supplemented with $10 \%$ fetal calf serum and $1 \%$ glutamine without antibiotics. OP-A was isolated from Drechslera gigantea as previously reported. ${ }^{34}$ The purity of OP-A (>95\%) was determined by RP-HPLC-UV.

Assessment of cell viability. The colorimetric MTT viability assay (3-(4,5dimethylthiazol-2-yl)-2,5 diphenyltetrazolium bromide; Sigma, Bornem, Belgium) was used to determine the overall growth level of each cell line at $72 \mathrm{~h}$ as described previously. ${ }^{35}$ The level of cell death was assessed by trypan blue (Sigma) exclusion and was calculated as the average percentage of dead cells in six fields per T25 flask at a magnification of $\mathrm{G} \times 10$ using an Olympus microscope (Olympus, Antwerp, Belgium). For the assessment of cell death after treatment with CHX (Sigma), U373-MG cells were seeded in 96-well plates. The next day, $0.25 \mu \mathrm{g} / \mathrm{ml} \mathrm{CHX}$ was added for $4 \mathrm{~h}$. Then, U373-MG cells were treated with $1 \mu \mathrm{M}$ OP-A for $24 \mathrm{~h}$, and the level of cell viability was determined using the colorimetric MTT assay.

Computer-assisted phase contrast microscopy (video microscopy). The effects of OP-A treatment on the viability of human U373-MG $(1 \mu \mathrm{M})$, T98G $(2 \mu \mathrm{M})$ and $\mathrm{GL} 19(4 \mu \mathrm{M}) \mathrm{GBM}$ cells were characterized in vitro using computer-assisted phase contrast video microscopy, as described elsewhere. ${ }^{36}$ 
Cell count-based determination of the GG indices: The GG indices obtained under the treated and control conditions were computed by quantitative video microscopy, dividing the number of cells at the 24th, 48th and 72nd hour of analysis by the number of cells at time 0 .

Quantitative determination of cell migration: The effect of OP-A $(1 \mu \mathrm{M})$ on cell motility in the U373-MG GBM cell line was investigated. Figure $3 \mathrm{c}$ shows typical analysis based on the individual cell trajectories that were established by a cell-tracking algorithm based on an image series acquired during a cell migration experiment. The greatest linear distance between the starting point of a cell and the farthest point reached in its trajectory, also known as the maximum relative distance from the point of origin (MRDO), was the quantitative variable used to characterize compound-mediated effects on cancer cell migration. ${ }^{37}$

Immunofluorescence/pseudo-confocal microscopy. U373-MG cells were cultured on glass coverslips, fixed with $4 \%$ paraformaldehyde, permeabilized in $0.2 \%$ Triton X-100 and stained as previously reported. ${ }^{38,39}$ Fluorescent phalloidin conjugated with Alexa Fluor 488 (Molecular Probes, Invitrogen, Merelbeke, Belgium) was used to label fibrillar actin, and Alexa Fluor 594-conjugated DNAse I (Molecular Probes, Invitrogen) was used to stain globular actin. U373-MG cells were probed with a rabbit anti- $\mathrm{K}_{\mathrm{Ca} 1.1}(\alpha$-subunit $\mathrm{BKCa})$ antibody $(1: 50$, Alomone Labs, Jerusalem, Israel). Mitochondria were stained with MitoTracker Green FM (100 nM; Invitrogen). The ER was stained with ER-Tracker Blue-White DPX (1 $\mu \mathrm{M}$, Invitrogen) for living cells or with a mouse anti-GRP78 antibody (1:100, Santa Cruz Biotech, Santa Cruz, CA, USA). Secondary antibodies were purchased from Pierce (Aalst, Belgium). Coverslips were mounted on microscope slides with $10 \mu \mathrm{l}$ of polyvinyl alcohol mounting medium with the DABCO antifading reagent (Fluka, Belgium). Three coverslips per experimental condition were analyzed, and three images were taken for each coverslip (with the same exposure time) with an AxioCam HRm fluorescence microscope (Zeiss, Oberkochen, Germany). The most representative images are shown.

Cytosolic Free $\mathrm{Ca}^{2+}$ Measurements. U373-MG cells, plated on $22 \mathrm{~mm}$ round glass coverslips, were incubated with $1 \mu \mathrm{M}$ Fura-2/AM (Calbiochem, Camarillo, CA, USA) in Krebs-HEPES buffer (10 mM HEPES, $135 \mathrm{mM} \mathrm{NaCl}, 6 \mathrm{mM}$ $\mathrm{KCl}, 2 \mathrm{mM} \mathrm{CaCl}, 1.2 \mathrm{mM} \mathrm{MgCl}_{2}, 10 \mathrm{mM}$ glucose, $\mathrm{pH} 7.4$ ) for $60 \mathrm{~min}$ at room temperature. Coverslips were then mounted in a microscope chamber. Cells were alternately excited $(1 \mathrm{~Hz})$ at 340 and $380 \mathrm{~nm}$ using a Lambda DG-4 Ultra High Speed Wavelength Switcher (Sutter Instrument, Novato, CA, USA) coupled to a Zeiss Axiovert $200 \mathrm{M}$ inverted microscope (Zeiss Belgium, Zaventem, Belgium). Images were acquired with a Zeiss Axiocam camera coupled to a 510-nm emission filter and analyzed with Axiovision software. Calcium concentration was evaluated from the ratio of fluorescence emission intensities excited at the two wavelengths using the Grynkiewicz equation. ${ }^{40}$

Flow cytometry. For cell cycle analyses, U373-MG cells were stained with $1 \mathrm{mg} / \mathrm{ml}$ propidium iodide (Sigma-Aldrich, Bornem, Belgium) containing $1 \mathrm{mg} / \mathrm{ml}$ RNase (Roche Diagnostics Gmbh, Mannheim, Germany) and analyzed using a Cell Lab Quanta SC FCM (Beckman Coulter; Analis, Suarlee, Belgium).

Apoptosis was detected using an assay measuring DNA fragmentation and annexin $V$ staining. The TUNEL assay was performed according to a previously described procedure ${ }^{32}$ with the APO-DIRECT Kit (BD Pharmingen, ErembodegemAalst, Belgium). The protocol provided by the manufacturer was followed, including the use of positive and negative controls. The appearance of phosphatidyl-serine on the extracellular side of the cell membrane was also quantified with the Alexa Fluor 488 Annexin V/Dead Cell Apoptosis Kit (Molecular Probes, Invitrogen) as recommended by the manufacturer using FCM.

AO (Sigma), used to stain acidic vacuoles (red staining: $568 \mathrm{~nm}$ ) and to stain membrane permeabilization of lysosomes (green staining: $488 \mathrm{~nm}$ ), was added at a final concentration of $1 \mathrm{mg} / \mathrm{ml}$ for a period of $15 \mathrm{~min}$. The stained cells were analyzed by a Cell Lab Quanta SC FCM (Beckman Coulter) and by an AxioCam HRm fluorescence microscope (Zeiss).

Immunoblotting. Membranes were blotted with anti-CD44 (1:2500, Abcam, Cambridge, UK), anti-nestin (1:60, Abcam), anti-PARP (1:250, BD Pharmingen, Erembodegem-Aalst, Belgium), anti-K $\mathrm{K}_{\mathrm{Ca} 1.1}(\alpha$-subunit BKCa; $1: 500$, Alomone Labs) and anti-tubulin (1:5000, Abcam). Secondary antibodies were purchased from Pierce, and the blots were analyzed using the Bio-Rad ChemiDoc XRS Imager (Bio-Rad Laboratories, Nazareth Eke, Belgium).
Senescence assay. Cell senescence analyses were performed according to a previously described procedure ${ }^{18}$ using the Senescence Cells Histochemical Staining Kit (Sigma), and the cells subsequently imaged using phase contrast microscopy. The protocol provided by the manufacturer was followed. Doxorubicin (100 nM)-treated A549 NSCLC cells were used as a positive control for SA- $\beta$-gal expression.

Electrophysiology (patch clamp). Whole-cell potassium currents were recorded as previously described. ${ }^{41}$ Briefly, U373-MG cells were seeded in $35-\mathrm{mm}$ petri dishes at $4000 \mathrm{cells} / \mathrm{cm}^{2}$. Before electrophysiological recording experiments, the growth medium was discarded and replaced with a physiological solution. Signals were captured using a 1322-A Digidata converter (Axon Instruments, Union City, CA, USA) and pClamp 8.1 software (Axon Instruments). The analyses were performed using Clampfit 8.1 and Origin 7.0 (Microcal Software, Northampton, MA, USA).

Statistical analysis. Data are the mean \pm S.E.M. The nonparametric MannWhitney U-test was used to compare data obtained from two independent groups. The statistical analysis was performed using Statistica software (StatSoft, Tulsa, OK, USA). A value of $P<0.05$ was considered statistically significant.

\section{Conflict of Interest}

The authors declare no conflict of interest.

Acknowledgements. Marina Bury is the holder of a FRIA grant from the Fonds National de la Recherche Scientifique (FNRS, Belgium) and Robert Kiss is a director of research at the FNRS. We thank Dr. Maurizio Vurro and Dr. Maria Chira Zonno, Istituto di Scienze delle Produzioni Alimentari, CNR, Bari Italy, who generously supplied the culture filtrates of $D$. gigantea.

1. Furnari FB, Fenton T, Bachoo RM, Mukasa A, Stommel JM, Stegh A et al. Malignant astrocytic glioma: genetics, biology, and paths to treatment. Genes Dev 2007; 21: 2683-2710.

2. Stupp R, Hegi ME, Mason WP, van den Bent MJ, Taphoorn MJ, Janzer RC et al. Effects of radiotherapy with concomitant and adjuvant temozolomide versus radiotherapy alone on survival in glioblastoma in a randomized phase III study: 5-year analysis of the EORTCNCIC trial. Lancet Oncol 2009; 10: 459-466.

3. McLendon R, Friedman A, Bigner D, Van Meir EG, Brat DJ, Mastrogianakis GM et al. Comprehensive genomic characterization defines human glioblastoma genes and core pathways. Nature 2008; 455: 1061-1068.

4. Sperandio S, de Belle I, Bredesen DE. An alternative, nonapoptotic form of programmed cell death. Proc Natl Acad Sci USA 2000; 97: 14376-14381.

5. Hoa NT, Zhang JG, Delgado CL, Myers MP, Callahan LL, Vandeusen G et al. Human monocytes kill M-CSF-expressing glioma cells by BK channel activation. Lab Invest 2007; 87: $115-129$

6. Sugawara F, Strobel G, Strange RN, Siedow JN, Van duyne GD, Clardy J. Phytotoxins from the pathogenic fungi Drechslera maydis and Drechslera sorghicola. Proc Natl Acad Sci USA 1987; 84: 3081-3085.

7. Au TK, Chick WS, Leung PC. The biology of ophiobolins. Life Sci 2000; 67: 733-742.

8. Tipton CL, Paulsen PV, Betts RE. Effects of ophiobolin A on ion leakage and hexose uptake by maize roots. Plant Physiol 1977; 59: 907-910.

9. Cocucci SM, Morgutti S, Cocucci M, Gianani L. Effects of ophiobolin A on potassium permeability, transmembrane electrical potential and proton extrusion in maize roots. Plant Sci Lett 1983; 32: 9-16.

10. Fujiwara $H$, Matsunaga $K$, Kumagai $H$, Ishizuka $M$, Ohizumi $Y$. Ophiobolin $A$, a novel apoptosis-inducing agent from fungus strain f-7438. Pharm Pharmacol Commun 2000; 6: 427-431.

11. Chen J, McKay RM, Parada LF. Malignant glioma: lessons from genomics, mouse models, and stem cells. Cell 2012; 149: 36-47.

12. Haar CP, Hebbar P, Wallace GC 4th, Das A, Vandergrift WA 3rd, Smith JA et al. Drug resistance in glioblastoma: a mini review. Neurochem Res 2012; 37: 1192-1200.

13. Van Meir EG, Kikuchi T, Tada M, Li H, Diserens AC, Wojcik BE et al. Analysis of the p53 gene and its expression in human glioblastoma cells. Cancer Res 1994; 54: 649-652.

14. Gomez-Manzano C, Fueyo J, Kyritsis AP, McDonnell TJ, Steck PA, Levin VA et al. Characterization of p53 and p21 functional interactions in glioma cells en route to apoptosis. J Natl Cancer Inst 1997; 89: 1036-1044.

15. Rottner K, Stradal TE. Actin dynamics and turnover in cell motility. Curr Opin Cell Biol2011; 23: $569-578$.

16. Mégalizzi V. Implication des récepteurs sigma et de leurs ligands dans la biologie des cancers. PhD Thesis, Université Libre de Bruxelles (ULB), 2011. Available at http:// 
theses.ulb.ac.be/ETD-db/collection/available/ULBetd-07042011-121707/unrestricted/ TheseVMegacorps.pdf.

17. O'Callaghan-Sunol C, Gabai VL, Sherman MY. Hsp27 modulates p53 signaling and suppresses cellular senescence. Cancer Res 2007; 67: 11779-11788.

18. Dimri GP, Lee X, Basile G, Acosta M, Scott G, Roskelley $C$ et al. A biomarker that identifies senescent human cells in culture and in aging skin in vivo. Proc Natl Acad Sci USA 1995; 92: 9363-9367.

19. Litwiniec A, Grzanka A, Helmin-Basa A, Gackowska L, Grzanka D. Features of senescence and cell death induced by doxorubicin in A549 cells: organization and level of selected cytoskeletal proteins. J Cancer Res Clin Oncol 2010; 136: 717-736.

20. Galvez A, Gimenez-Gallego G, Reuben JP, Roy-Contancin L, Feigenbaum P, Kaczorowsk GJ et al. Purification and characterization of a unique, potent, peptidyl probe for the high conductance calcium-activated potassium channel from venom of the scorpion Buthus tamulus. J Biol Chem 1990; 5: 11083-11090.

21. Ransom CB, Sontheimer H. BK channels in human glioma cells. J Neurophysiol 2001; 85 790-803.

22. Weaver AK, Liu X, Sontheimer H. Role for calcium-activated potassium channels (BK) in growth control of human malignant glioma cells. J Neurosci Res 2004; 15: 224-234.

23. Candia S, Garcia ML, Latorre R. Mode of action of iberiotoxin, a potent blocker of the large conductance $\mathrm{Ca}^{(2+)}$-activated $\mathrm{K}^{+}$channel. Biophys J 1992; 63: 583-590.

24. Kaczorowski GJ, Knaus HG, Leonard RJ, McManus OB, Garcia ML. High-conductance calcium-activated potassium channels; structure, pharmacology, and function. J Bioenerg Biomembr 1996; 28: 255-267.

25. Orio P, Rojas P, Ferreira G, Latorre R. New disguises for an old channel: MaxiK channel beta-subunits. News Physiol Sci 2002; 17: 156-161.

26. McManus OB, Helms LM, Pallanck L, Ganetzky B, Swanson R, Leonard RJ. Functional role of the $\beta$ subunit of high conductance calcium-activated potassium channels. Neuron 1995; 14: 645-650.

27. Sontheimer H. An unexpected role for ion channels in brain tumor metastasis. Exp Bio Med 2008; 233: 779-791

28. Furukawa R, Maselli A, Thomson SA, Lim RW, Stokes JV, Fechheimer M. Calcium regulation of actin crosslinking is important for function of the actin cytoskeleton in Dictyostelium. J Cell Sci 2003; 116: 187-196.

29. Weaver AK, Bomben VC, Sontheimer H. Expression and function of calcium-activated potassium channels in human glioma cells. Glia 2006; 54: 223-233.

30. Grunnet M, Kaufmann WA. Coassembly of big conductance $\mathrm{Ca}^{2+}$-activated $\mathrm{K}^{+}$channels and L-type voltage-gated $\mathrm{Ca}^{2+}$ channels in rat brain. J Biol Chem 2004; 279: 36445-36453.

31. Calenda G, Suadicani SO, Iglesias R, Spray DC, Melman A, Davies KP. Silencing MaxiK activity in corporal smooth muscle cells initiates compensatory mechanisms to maintain calcium homeostasis. J Sex Med 2011; 8: 2191-2204.
32. Lallemand B, Chaix F, Bury M, Bruyère C, Ghostin J, Becker JP et al. N-(2-\{3-[3,5bis(trifluoromethyl)phenyl]ureido\}ethyl)-glycyrrhetinamide(6b): a novel anticancer glycyrrhetinic acid derivative that targets the proteasome and displays anti-kinase activity. J Med Chem 2011; 54: 6501-6513.

33. Berger W, Spiegl-Kreinecker S, Buchroithner J, Elbling L, Pirker C, Fischer J et al. Overexpression of the human major vault protein in astrocytic brain tumor cells. Int $\mathrm{J}$ Cancer 2001; 94: 377-382

34. Evidente A, Andolfi A, Cimmino A, Vurro M, Fracchiolla M, Charudattan R. Herbicidal potential of ophiobolins produced by Drechslera gigantea. J Agric Food Chem 2006; 54: 1779-1783.

35. Mosmann T. Rapid colorimetrie assay for cellular growth and survival: application to proliferation and cytotoxicity assays. J Immunol Meth 1983; 65: 55-63.

36. Debeir O, Mégalizzi V, Warzée N, Kiss R, Decaestecker C. Video-microscopic extraction of specific information on cell proliferation and migration in vitro. Exp Cell Res 2008; 314: 2985-2998.

37. Mégalizzi V, Decaestecker C, Debeir O, Spiegl-Kreinecker S, Berger W, Lefranc F et al. Screening of anti-glioma effects induced by sigma-1 receptor ligands: potential new use for old anti-psychiatric medicines. Eur J Cancer 2009; 45: 2893-2905.

38. Mégalizzi V, Mathieu V, Mijatovic T, Gailly P, Debeir O, De Neve N et al. 4-IBP, a sigma1 receptor agonist, decreases the migration of human cancer cells, including glioblastoma cells, in vitro and sensitizes them in vitro and in vivo to cytotoxic insults of proapoptotic and proautophagic drugs. Neoplasia 2007; 9: 358-369.

39. Le Calvé B, Rynkowski M, Le Mercier M, Bruyère C, Lonez C, Gras T et al. Long-term in vitro treatment of human glioblastoma cells with temozolomide increases resistance in vivo through up-regulation of GLUT transporter and aldo-keto reductase enzyme AKR1C expression. Neoplasia 2010; 12: 727-739.

40. Grynkiewicz G, Poenie M, Tsien RY. A new generation of $\mathrm{Ca} 2+$ indicators with greatly improved fluorescence properties. J Biol Chem 1985; 260: 3440-3450.

41. Roger S, Potier M, Vandier C, Le Guennec JY, Besson P. Description and role in proliferation of iberiotoxin-sensitive currents in different human mammary epithelial normal and cancerous cells. Biochim Biophys Acta 2004; 1667: 190-199.

(c) (1) $\Theta$ Cell Death and Disease is an open-access journal By ${ }_{\mathrm{NC}}$ poblished by Nature Publishing Group. This work is licensed under a Creative Commons Attribution-NonCommercialNoDerivs 3.0 Unported License. To view a copy of this license, visit http://creativecommons.org/licenses/by-nc-nd/3.0/ 